\title{
Preliminary Canter of the Accident Rate in Italian and Lithuanian Road Networks
}

\author{
Mariarosaria Busiello ${ }^{\mathrm{a}}$, Kornelija Ratkevičiūte $\dot{\mathrm{b}}^{\mathrm{b}}$, Daiva Žilionienè $\dot{e}^{\mathrm{b}}$, Francesca Russo ${ }^{\mathrm{c}}$, \\ Salvatore Antonio Biancardo ${ }^{c}$, Gianluca Dell'Acqua ${ }^{c}$ \\ ${ }^{a}$ Villanova University, 800 East Lancaster Avenue, Villanova, Pennsylvania 19087, USA \\ ${ }^{b}$ Vilnius Gediminas Technical University, Saulètekio al. 11, 10223 Vilnius, Lithuania \\ ${ }^{c}$ University of Naples Federico II, Via Claudio, 25 I-80125 Naples, Italy
}

\begin{abstract}
One of the major tasks in developing transport systems is to decrease human losses caused by traffic accidents. The social consequences of accidents and the relating human losses were the main reason why the European Ministers of Transport decided to take measurements in 2002 and then in 2010 in order to decrease the number of traffic accident related deaths in Member States Italian and Lithuanian researchers have developed national statistical methods to answer to European directives in their own country. The aim of this research study is to investigate the safety conditions of Italian and Lithuania two-lane rural roads in order to figure out why accidents occur and by what means they can be avoided. Current safety situation needs to be known for selecting locations to be treated as well as for evaluating the effects. In fact the deaths of persons and serious economic loss caused by road crashes demand a continuous attention in accordance with the rapid population growth and increasing economic activities that have resulted in many European cities. A study period of 5 years of the accident database was investigated in order to estimate the hazard conditions for each road segment by comparing the number of crashes over a specific roadway segment over a specific time period with statistically thresholds. In this way, by knowing critical road segments, it makes to define a consistent combination of interventions according also to the difference between design and operating speed value reducing accident frequency, its severity and social cost for the more frequently expected and dangerous accident scenario. Further investigations on accident types in defined most hazardous road segments, i.e. where calculated severe crash rate, must be analyzed and selected road safety measures for improving safety situation at a site.
\end{abstract}

Keywords: homogenous road groups; accident rates;network safety approach;accident type;road safety; critical value.

\section{Introduction and literary review}

Road crashes are one of the most important problems being faced by modern societies. Apart from the humanitarian aspect of reducing road deaths and injuries in developing crashes, a strong case can be made for reducing road crash deaths on economic grounds alone, as they consume massive financial resources that the countries can ill afford to lose. The deaths of persons and serious economic loss caused by road crashes demand a continuous attention in accordance with the rapid population growth and increasing economic activities that have resulted in the huge growth of motor vehicles. When roads are improved, road accident rate will come down. Though the overall death rate has decline and expectation of life has gone up, the death risk on roads has considerably increased.

The European Commission (EC) adopted the directive 2008/96/EC [1] that requires the establishment of procedures relating to road safety impact assessments, road-safety audits, management of road network safety, and safety inspection for roads to design, under construction, or in operation. The results of its implementation in the member states are forthcoming. In Italy, the European directive is acknowledged in the Legislative Degree number 35/2011 whose purpose is to guide, to coordinate and to standardize the activities of all involved in road infrastructure safety.

It is clear that the main goal of roadway safety analyses is to identify locations with a high risk of crashes, called hot spots, in order to reduce the number and severity of crashes. Many state and local transportation agencies recognize that accurate identification of hot spots is an important first step in the effective use of their limited safety funds [2].

Corresponding author: Mariarosaria Busiello. E-mail address: mariarosaria.busiello@villanova.edu

http://dx.doi.org/10.3846/enviro.2014.149

(C) 2014 The Authors. Published by VGTU Press. This is an open-access article distributed under the terms of the Creative Commons Attribution License, which permits unrestricted use, distribution, and reproduction in any medium, provided the original author and source are credited. 
Peltola et al. [3] highlight the need for development of reliable, easily and user-friendly safety evaluation tools that are scientifically well founded. They introduce the basis and principles of two evaluation tools and report on the experience of using them internationally. The first tool is based on the Empirical Bayesian method and is designed to evaluate the current safety situation and safety effects of road improvements. The second tool helps define the specific characteristics of accidents and compare them between countries.

Peltola et al. [4] describe the scope of road safety audits (RSA), network safety ranking (NSR) and road safety inspections (RSI) procedures prepared in the frame of BALTRIS project, and provide detailed implementation and execution of procedures for the EU Member States.

Dell'Acqua et al. [5] plot density diagrams per road crash risk type to identify all possible scenarios where driving is less than safe. The starting point was the prediction of injury crash rate on horizontal homogeneous segments of two-lane rural roads for three main injurious crash types (head-on \% side collisions, rear-end crashes, and single-vehicle run-off-road crashes) as observed on the network. A careful analysis of the database shows that factors such as the road scenario, mean lane width, the horizontal curvature indicator and the mean speed appear to be influenced or associated with the crash dynamic. Risk type density charts were plotted to thoroughly identify all possible combinations of existing explicative variables producing hazardous conditions on the road. The different shades in the diagrams represent different ranges of injurious crash rates. The risk maps makes possible to keep under control in a simple and immediate approach the way each variable as a result of variations of a part or of all.

Russo et al. [6] develop safety performance functions (SPFs) on two-lane rural roads to predict the number of injury crashes per year per $10^{8}$ vehicles $/ \mathrm{km}$ on the road segment using a study on the influence of the human factors (gender, age, number of drivers) and road scenario (combination of infrastructure and environmental conditions found at the site at the time of the crash) on the effects of a crash by varying the dynamic. According to the current study, based on the network approach for the allocation of economic resources and planning of road safety strategies, calibration of injury crash rate prediction models for specific target collision type is important because of the range of harms that are caused by different collision types. Countermeasures are suggested to reduce the injury crash rate and include different awareness campaigns and structural measures on the segments of road. Before-and-after safety evaluations can be used to check the safety benefits of improvements carried out on the roadways, within budget constraints for improvement or safety compliance investments for future operation.

This study illustrates a "network" approach in order to identify the "black" roadway segments where the accident rate is higher than on the rest of the road studied path. This experimental analysis is the first step of a larger study that aims to enhance international co-operation, with a view to improving performance and safety.

Five criteria are used in Lithuania to classify roads:

1) road type;

2) rural or urban area;

3) cross section;

4) speed limit;

5) AADT.

Following these criteria similarities between Italian and Lithuanian roads were found, in fact the research described in this paper aims to study safety conditions of road segments located in the Southern Italy and in Lithuania by using the assessment of the accident rates and the critical accident rate.

An additional careful study for most critical homogeneous segment with high accident rate was made by analyzing the accident type in order to determine potential countermeasures that can help to reduce the accident frequency.

\section{Lithuania data collection and analysis}

The aim of this chapter is to present safety situation of the two-lane rural roads of network national significance of Lithuania. The roads of Lithuania according to their capacity, social and economic significance are divided into roads of national and local significance. Total length of the roads of national significance of Lithuania is $21241 \mathrm{~km}$ of which:

- Main roads - $1746 \mathrm{~km}$;

- National roads - $4929 \mathrm{~km}$;

- Regional roads - $14566 \mathrm{~km}$.

Seeking to find which road takes the biggest part in the road network the data of TARVA LT tool were used. The purpose of TARVA LT is to provide a common method, database and user interface for predicting the expected number of road accidents for selecting locations for safety treatments, and estimating the safety effects of road safety improvements in order to evaluate the cost-effectiveness of combinations of safety measures. The underlying logic of TARVA is combining general safety (accident model) with information from local safety factors (accident record) using the Empirical Bayesian (EB) method. For creating accident prediction models, the road network is divided into homogeneous road sections and crossings. [4] TARVA is used to evaluate all the safety effects of road improvements on public roads in Finland for more than 15 years, and an enhanced TARVA is developed for Lithuanian road and Finnish level crossings. These programs operate on the Internet using user names and passwords [3]. 
In order to divide road network into homogenous road sections the five year data on road accidents, traffic volume, road parameters and the surrounding environment was collected. Based on the mentioned data the road network of Lithuania was divided separately into separate groups and subgroups of roads and junctions [7].

Three groups of roadway width (less of $6 \mathrm{~m}$, from $6 \mathrm{~m}$ to $9 \mathrm{~m}$, more than $9 \mathrm{~m}$ ) were investigated to choose the one with the bigger number of kilometers to analyze (Table 1 ).

Table 1. The two-lane rural roads network of national significance of Lithuania with roadway

\begin{tabular}{|c|c|c|c|}
\hline Road width, m & Homogenous road group & AADT,vpd & Total length, km \\
\hline \multicolumn{4}{|l|}{$1 . \leq 6 \mathrm{~m}$} \\
\hline & & $<1500$ & 4152.79 \\
\hline V category & Minor road, $\leq 6 \mathrm{~m}$ & $\begin{array}{c}1500-4500 \\
\geq 4500 \\
\text { Total, } \mathbf{k m :}\end{array}$ & $\begin{array}{c}612.81 \\
16.65 \\
\mathbf{4 7 8 2 . 2 5}\end{array}$ \\
\hline \multicolumn{4}{|l|}{$2.6-9 \mathrm{~m}$} \\
\hline $\begin{array}{l}\text { 2.1.7.1-8.0m } \\
\text { III category }\end{array}$ & Main road, $8 \mathrm{~m}$ & $\begin{array}{l}<4500 \\
\geq 4500\end{array}$ & $\begin{array}{c}239.65 \\
49.16\end{array}$ \\
\hline $\begin{array}{l}\text { 2.2.6.1-7.0 m } \\
\text { IV category }\end{array}$ & Main road, $\leq 7 \mathrm{~m}$ & $\begin{array}{l}<4500 \\
\geq 4500\end{array}$ & $\begin{array}{l}27.07 \\
57.58\end{array}$ \\
\hline $\begin{array}{l}\text { 2.3.7.1-8.0 m } \\
\text { III category }\end{array}$ & Minor road, $8 \mathrm{~m}$ & $\begin{array}{c}<1500 \\
1500-4500 \\
\geq 4500\end{array}$ & $\begin{array}{c}213.60 \\
676.34 \\
96.26\end{array}$ \\
\hline $\begin{array}{l}\text { 2.4. } 6.1-7.0 \mathrm{~m} \\
\text { IV category }\end{array}$ & Minor road, $7 \mathrm{~m}$ & $\begin{array}{c}<1500 \\
1500-4500 \\
\geq 4500 \\
\text { Total, km: }\end{array}$ & $\begin{array}{c}2018.18 \\
802.30 \\
89.25 \\
\mathbf{4 2 6 9 . 3 9}\end{array}$ \\
\hline \multicolumn{4}{|l|}{ 3. $\geq 9 \mathrm{~m}$} \\
\hline \multirow[t]{2}{*}{ II category } & Main road, $9 \mathrm{~m}$ & $\begin{array}{c}<3000 \\
3000-6000 \\
\geq 6000\end{array}$ & $\begin{array}{c}83.55 \\
413.59 \\
265.34\end{array}$ \\
\hline & Minor road, $9 \mathrm{~m}$ & $\begin{array}{c}<4500 \\
\geq 4500 \\
\text { Total, } \mathbf{k m :}\end{array}$ & $\begin{array}{c}219.06 \\
94.40 \\
\mathbf{1 0 7 5 . 9 4}\end{array}$ \\
\hline
\end{tabular}

Table 1 shows that the biggest part from all Lithuanian road network is the $\mathrm{V}$ category National and Regional roads of national significance of Lithuaniawith width less than $6 \mathrm{~m}$ and AADT less than $1500 \mathrm{vpd}$ ("341. Minor road, $\leq 6 \mathrm{~m}$ " homogeneous road group in the TARVA LT program, total length of these roads is $4152.79 \mathrm{~km}$, number of homogeneous road sections - 2630.So, this group of roads was analyzed in more detail. Analyzed road group consists of 2630 homogenous road sections $j=2630$; study period is five years $P=5$; total number of accidents within five years period in road group is $\sum N=1023$; total length of all homogeneous road sections in the analyzed group is $\sum L=4152.79 \mathrm{~km}$; weighted average annual daily traffic of the road group is $Q_{w}=504 \mathrm{vpd}$.

When analyzing current safety, it is necessary to know the characteristics of accidents on the road network where safety actions are being planned. Accident analysis in the road group was carried out by using ONHA LT program. A safety evaluation tool called ONHA has been created for easy analysis of all the data from accidents, vehicles involved in accidents, and persons in those vehicles. ONHA is an analysis tool that operates on the Internet on a log-in basis. Currently there are versions on Finnish and Lithuanian public roads operating in several languages. The system allows statistical analysis of accident distributions (Chi-squared test).The analysis tool enables classification of data and makes it possible to use needed restrictions on the used data and variables. It is possible to group and study accident data using different criteria, to produce graphs and tables on data and to make statistical comparisons of data distributions. [3] The ONHA LT database contains accident data in Lithuanian road network since 2006.

During five year period in analyzed road group 1023 injury accidents occurred, 217 people were killed and 1376 were injured during those accidents. The main accident types were rollover (37\%) and collision (21\%) (Table 2).

Table 2. Distribution of casualty accidents types and their consequences in the "Minor road, $\leq 6$ m" group in the five years study period (Lithuanian data)

\begin{tabular}{|c|c|c|c|c|c|}
\hline \multirow{2}{*}{$\begin{array}{l}\text { Accident type } \\
\text { Rollover }\end{array}$} & Casualty accidents & \multicolumn{2}{|c|}{ Killed } & \multicolumn{2}{|c|}{ Injured } \\
\hline & $37 \%$ & 58 & $27 \%$ & 522 & $38 \%$ \\
\hline Collision & $21 \%$ & 45 & $21 \%$ & 369 & $27 \%$ \\
\hline Running to pedestrian & $108 \quad 11 \%$ & 41 & $19 \%$ & 73 & $5 \%$ \\
\hline Collision with bicycle & $8 \%$ & 20 & $9 \%$ & 68 & $5 \%$ \\
\hline Other accident & $6 \%$ & 13 & $6 \%$ & 94 & $7 \%$ \\
\hline Collision with stationary vehicle & $1 \%$ & 0 & $0 \%$ & 16 & $1 \%$ \\
\hline Collision with motorcycle & $0 \%$ & 0 & $0 \%$ & 3 & $0 \%$ \\
\hline Collision with moped & $0 \%$ & 0 & $0 \%$ & 0 & $0 \%$ \\
\hline Running to animal & $0 \%$ & 0 & $0 \%$ & 0 & $0 \%$ \\
\hline Collision with light train & $0 \%$ & 0 & $0 \%$ & 0 & $0 \%$ \\
\hline Totals & $100 \%$ & 217 & $100 \%$ & 1376 & $100 \%$ \\
\hline
\end{tabular}


Next step of the study is to identify the most hazardous road sections in respect of road safety where the number of accidents is higher than that on the other road sections similar in their environment. The potentially dangerous road sections are referred to those sections where the values of accidents are higher than the critical value of accidents of a homogenous group.

The suggested procedure can be summarized as follows:

Determine the road segments $(j)$ into the road path and associate the study period $(P)$ the relative total number of crashes $\left(N_{j}\right)$, length $\left(L_{j}\right)$, number of vehicles per day over the period $\left(Q_{j}\right)$

Determine the accident rate $R_{j}$ for each segment defined as the number of crashes per year per km per $10^{6}$ vehicles (accident frequency over traffic exposure) as follows:

$$
R_{j}=\frac{10^{6} \sum N_{j}}{365 P Q_{w} L_{j}} .
$$

Determine the mean accident rate $R_{r p}$ for the reference population as follows:

$$
R_{r p}=\frac{10^{6} \sum N_{j}}{365 P Q_{w} \sum L_{j}},
$$

where $Q_{w}$ is the weighted average annual daily traffic defined as follows:

$$
Q_{w}=\frac{\sum\left(Q_{j} L_{j}\right)}{\sum L_{j}}
$$

Determine the minimum accident rate that warrants a detailed safety analysis $I_{T}$, see Eqn. (4) and the critical accident rate (see Eqn. (5)) as follows:

$$
\begin{gathered}
I_{T}=2 R_{r p}, \\
R_{c j}=R_{r p}+K \sqrt{\frac{R_{r p} 10^{6}}{365 P L_{j} Q_{j}}}+\frac{10^{6}}{730 P L_{j} Q_{j}},
\end{gathered}
$$

where $K$ is the constant of the Poisson probability distribution equal to 1,645 with error margin never exceeded $10 \%$.

Accident level assignment for $j$-th road segment were calculated by the Eqn. (6):

\begin{tabular}{|c|c|c|c|c|c|}
\hline \multirow{2}{*}{\multicolumn{2}{|c|}{$\begin{array}{c}\text { Low crash rate } \\
\qquad R_{j} \leq I_{T}\end{array}$}} & \multirow{2}{*}{\multicolumn{2}{|c|}{$\begin{array}{c}\text { Moderate crash rate } \\
\qquad I_{T} \leq R_{j} \leq R_{c j}\end{array}$}} & \multirow{2}{*}{\multicolumn{2}{|c|}{$\begin{array}{l}\text { Severe crash rate } \\
\qquad R_{j} \geq R_{c j}\end{array}$}} \\
\hline & & & & & \\
\hline $\begin{array}{c}\text { Number of road } \\
\text { sections }\end{array}$ & $\begin{array}{l}\text { Proportion with all } \\
\text { road group }\end{array}$ & $\begin{array}{c}\text { Number of road } \\
\text { sections }\end{array}$ & $\begin{array}{l}\text { Proportion with all } \\
\text { road group }\end{array}$ & $\begin{array}{c}\text { Number of road } \\
\text { sections }\end{array}$ & $\begin{array}{l}\text { Proportion with all } \\
\text { road group }\end{array}$ \\
\hline 2260 & $86 \%$ & 268 & $10 \%$ & 102 & $4 \%$ \\
\hline
\end{tabular}

$$
R_{j} \leq I_{T} \text { Lowcrashrate } \quad I_{T} \leq R_{j} \leq R_{c j} \text { Moderatecrashrate } \quad R_{j} \geq R_{c j} \text { Severecrashrate }
$$

Results are presented in the Table 4.

Table 3. Accident level of the analysed road group (Lithuanian data)

Analysis showed that during five years road segments with high accident rates occurred in $4 \%$ of cases $(193,13 \mathrm{~km})$, with low accident rates in $86 \%$ of cases $(3395.17 \mathrm{~km})$ and with moderate accident rates in $10 \%$ of cases $(564,49 \mathrm{~km})$. Further investigations on accident types in defined most hazardous road segments, i.e. where calculated severe crash rate, must be analyzed and selected road safety measures for improving safety situation at a site.

\section{Italian data collection and analysis}

Salerno rural roads network extends for $3074 \mathrm{~km}$. A further classification is made according area crossed:

- Urban roads $(310 \mathrm{~km})$, when they cross areas with a population density of 2000-2500 habitants per km2;

- Suburban roads $(539 \mathrm{~km})$ when they cross areas with a population density less than 2000-2500 habitants per km2;

- Rural roads $(2225 \mathrm{~km})$ when they cross no urban areas.

The accident data used in the research presented here involved $2225 \mathrm{~km}$ of two-lane rural road in Southern Italy located in the flat area with a vertical grade of less than $6 \%$.

Crash data were made available to the Department of Civil, Architectural and Environmental Engineering at the University of Naples by the Administration of the Province of Salerno.

Following Lithuanian criterion two-lane rural roads were selected. Three groups of roadway width (less of $6 \mathrm{~m}$, from $6 \mathrm{~m}$ to $9 \mathrm{~m}$, more than $9 \mathrm{~m}$ ) were investigated to choose the one with the bigger number of kilometers to analyze; $898.67 \mathrm{~km}$ of the total rural network studied come into the first group, $1248.14 \mathrm{~km}$ come into the second group and $78.11 \mathrm{~km}$ come into the third group. To find similarities with Lithuanian roads, the last two criteria, explained below, were followed for the first 
group: speed limit was constant and equal to $90 \mathrm{~km} / \mathrm{h}$, and three groups of AADT (less of $1500 \mathrm{vpd}$, from $1500 \mathrm{vpd}$ to $4500 \mathrm{vpd}$, more than $4500 \mathrm{vpd}$ ) were investigated, as showed in Table 1 for Lithuanian roads. $612.85 \mathrm{~km}$ come into the first group, $241.61 \mathrm{~km}$ come into the second group and $44.21 \mathrm{~km}$ come into the third group. The firsts group shows the bigger number of kilometers so it was choose for further analysis.

Analyzed road group consists of 133 homogenous road sections; over the selected road segments of the network analyzed, 40 crashes can be observed in a study period in five years with 64 injuries and 8 deaths.

To deeply analyze safety conditions accident rates were calculated in order to estimate the hazard conditions for each road segment by comparing the number of crashes over a specific roadway segment over a specific time period with statistically thresholds. For this purpose it is needed to determine:

- Accident rate $\mathrm{Rj}$ in each homogenous road section $\mathrm{j}$ by the Eqn. (1),

- Mean accident rate Rrp for the all homogenous road group by the Eqns (2)-(3);

- Minimum accident rate that warrants a detailed safety analysis "IT" by the Eqn. (4);

- Critical accident rate Rcj in each homogenous road section $\mathrm{j}$ by the Eqn. (5).

Analysis showed that during five years road segments with high accident rates occurred in 3\% of cases (19.81 km), with low accident rates in $80 \%$ of cases $(489.53 \mathrm{~km})$ and with moderate accident rates in $17 \%$ of cases $(103.51 \mathrm{~km})$.

Accident level assignment for each $j$-th road segment is:

- Low crash rate, when $\mathrm{Rj} \leq \mathrm{IT}$;

- Moderate crash rate, when $\mathrm{IT} \leq \mathrm{Rj} \leq \mathrm{Rcj}$;

- Severe crash rate, when $\mathrm{Rj} \geq \mathrm{Rcj}$.

Table 4 shows in detail the summary of the main features for the studied road segments with a severe accident rate for a five years study period.

Table 4. Accident types for the analyzed road segments (Italian data)

\begin{tabular}{cccc}
\hline No & Length, km & $\begin{array}{c}\text { Accident Rate, } \\
\text { acc/Mveh-km }\end{array}$ & $\begin{array}{c}\text { Critical Accident Rate, } \\
\text { acc/Mveh-km }\end{array}$ \\
\hline 1 & 1.692 & 6.476 & 3.143 \\
3 & 0.662 & 040 & 0.744 \\
4 & 6.605 & 0.608 & 0.315 \\
5 & 2.924 & 0.290 & 0.196 \\
\hline
\end{tabular}

Further investigations on accident types in defined most hazardous road segments, i.e. where calculated severe crash rate, must be analyzed and selected road safety measures for improving safety situation at a site.

\section{Discussion}

The research presented here aims to assess the level of the accident rate at each homogeneous road segment by a comparison with standard Italian thresholds. $898.67 \mathrm{~km}$ of two-lane rural network in Southern Italy, and $4152.79 \mathrm{~km}$ of twolane rural network in Lithuania were investigated.

A study period of 5 years of the accident database was investigated in order to estimate the hazard conditions for each road segment by comparing the number of crashes over a specific roadway segment over a specific time period with statistically thresholds. In this way, by knowing critical road segments, it makes to define a consistent combination of interventions according also to the difference between design and operating speed value reducing accident frequency, its severity and social cost for the more frequently expected and dangerous accident scenario.

By analyzing the accident rates, along the Southern Italy roads were identified $489.53 \mathrm{~km}(80 \%)$ with a low accident rate, $19.81 \mathrm{~km}(3 \%)$ with a high accident rate, and $103.51 \mathrm{~km}(17 \%)$ of road segments with a medium accident rate.

Along the Lithuanian roads, road segments with high accident rates occurred in $4 \%$ of cases (193.13 km), with low accident rates in $86 \%$ of cases $(3395.17 \mathrm{~km})$ and with moderate accident rates in $10 \%$ of cases $(564.49 \mathrm{~km})$.

Results show that in both countries the group of roadway segments with a width that is less of $6 \mathrm{~m}$ and an AADT of less than 1500 vpd has mostly a low accident rate while only very few road segments show a severe rate. The percentage of road segments with a severe accident rate is quite the same in both countries that is why further investigations on accident types in defined most hazardous road segments have to be analyzed and selected road safety measures for improving safety situation at a site.

Future development of research addresses a) the investigation of driver speed behavior on road segments associated with severe accident rates, b) the improvement of the accident information, c) before-after analysis compared the results of a simulated setting with real implementation solution to check the reliability of the proposed alternatives improving the safety conditions. 


\section{Conclusions}

1. In order to divide Lithuanian and Southern Italian road networks into homogenous road sections the five year data on road accidents, traffic volume, road parameters and the surrounding environment was collected.

2. $28 \%$ of two-lane rural network in Lithuania and $72 \%$ of two-lane rural network in Southern Italy were investigated. The roadway of investigated roads was less of $6 \mathrm{~m}$ and the Annual Average Daily Traffic was less of 1500 vehicles per day.

3. Lithuanian and Southern Italy road networks analysis showed that during five years road segments with high accident rates occurred in 4\% (Lithuania) and in 3\% (Southern Italy) of cases, with moderate accident rates in $10 \%$ of cases (Lithuania) and in $17 \%$ (Southern Italy) of cases and with low accident rates in $86 \%$ (Lithuania) and $80 \%$ (Southern Italy) of cases.

4. Further investigations on accident types in defined most hazardous road segments, where calculated severe crash rate, must be analyzed to selected road safety measures for improving safety situation at a site.

\section{References}

[1] European Parliament and the Council on Road Infrastructure Safety Management. 2008. Directive 2008/96/EC, Official Journal of the European Union 29.11.2008: L319/59-L319/67.

[2] Lim, I.; Kweon, Y. 2013. Identifying High-Crash-Risk Intersections Comparison of Traditional Methods with the Empirical Bayes-Safety Performance Function Method, Transportation Research Record: Journal of the Transportations Research Board 2364: 44-50. http://dx.doi.org/10.3141/2364-06

[3] Peltola, H.; Rajamaki, R.; Luoma, J. 2012. Tools Needed for Enhancing Transferability of Cost-Effective Road Safety Measures, in Procedia - Social and Behavioral Science 48: 1234-1243. http://dx.doi.org/10.1016/j.sbspro.2012.06.1099

[4] Peltola, H.; Ratkevičiūtè, K.; Jasiūnienè, V.; Virkkunen, M. 2013. Road Network Safety Tools Needed for Enhancing Transferability of Cost-Effective Road Safety Measures Management Using the Tarva Tool, in Proc. of the XXVIII International Baltic Road Conference. Vilnius 26-28August.

[5] Dell'Acqua, G.; Russo, F.; Biancardo, S. A. 2013. Risk-type density diagrams by crash type on two-lane rural roads, Journal of Risk Research 16(10): 1297-1314. http://dx.doi.org/10.1080/13669877.2013.788547

[6] Russo, F.; Biancardo, S. A.; Dell'acqua, G. 2014. Road Safety from the Perspective of Driver Gender and Age as Related to the Injury Crash Frequency and Road Scenario, Traffic Injury Prevention 15(1): 25-33. http://dx.doi.org/10.1080/15389588.2013.794943

[7] Jasiūnienè, V.; Čygas, D.; Ratkevičiūtè, K. Peltola, H. 2012. Safety ranking of the Lithuanian road network of national significance, The Baltic Journal of Road and Bridge Engineering 7(2): 129-136. http://dx.doi.org/10.3846/bjrbe.2012.18 